\title{
Time Evolution of Structural and Magnetic Properties of Ni-Zn Nano Ferrite: An Opinion
}

\author{
Raghuvanshi $\mathrm{S}^{1}$, Mazaleyrat $\mathrm{F}^{2}$ and Kane $\mathrm{SN}^{1 *}$ \\ ${ }^{1}$ Magnetic Materials Laboratory, School of Physics, DA University, Indore-452001, India \\ ${ }^{2}$ SATIE, ENS, Universite Paris-Saclay, 61 Av. du Pdt. Wilson, F-94230, Cachan, France
}

Submission: April 08, 2017; Published: May 04, 2017

*Corresponding author: Kane SN, School of Physics, DA University, India, Email: kane_sn@yahoo.com

Abstract

We give our view on the time evolution of structural, magnetic properties, cationic distribution in $\mathrm{Ni}_{0.5} \mathrm{Zn}_{0.5} \mathrm{Fe}_{2} \mathrm{O}_{4}$ nano particles synthesized via sol gel auto combustion method. This distinctive study eventually provides an insight on most favorable synthesis time to get needed structural, magnetic properties needed for various applications eg- in heterogeneous catalysis, medical applications.

Keywords: Spinel ferrite; Time evolution of properties; XRD; Cation distribution; Magnetic properties

\section{Opinion}

In spinel nano ferrites their synthesis procedure, particle size, crystallinity and allocation of cations on tetrahedral A and octahedral B site plays a key role in determining their physical properties [1]. To have precise control on properties, time associated with synthesis process becomes a key parameter and in this context real-time monitoring of properties is important as well [2,3]. Thus, time evolution of synthesis process comprising a potential strategy for complete understanding of the involved formation mechanism is of fundamental importance in the nano particles synthesis, to have control on their properties, is important to have cost effective mass production [3].

$\mathrm{Ni}-\mathrm{Zn}$ polycrystalline spinel ferrites nano particles are intensively studied both theoretically and practically owing to their low toxicity, chemical stability, mechanical hardness and reasonable cost [4]. Properties of the Ni-Zn ferrite are quite susceptible to the preparation method, the amount of substituting elements and their species [5]. Ni ferrite: inverse ferrite, Zn ferrite: normal ferrite [6], thus Ni-Zn ferrite. Ni$\mathrm{Zn}$ ferrite thus is expected to exhibit mixed spinel structure, with strong preference of $\mathrm{Zn}, \mathrm{Ni}$ ions to occupy respectively tetrahedral (A site), octahedral (B site) where cationic distribution can be shown by $\left(\mathrm{Zn}_{\mathrm{x}} \mathrm{Fe}_{1-\mathrm{x}}\right)^{\mathrm{A}}\left[\mathrm{Ni}_{1-\mathrm{x}} \mathrm{Fe}_{2-\mathrm{x}}\right]^{\mathrm{B}} \mathrm{O}_{4}$.

Existing literature on $\mathrm{Ni}-\mathrm{Zn}$ ferrites report correlation between structural, magnetic properties [7] but, it does not reveal essential study on time evolution of structural, magnetic properties of Ni-Zn ferrite. Thus, a study on time evolution of
Ni-Zn ferrite essentially will fill the gap between laboratory researches and, the scale-up industrial production of nanomaterials with desired properties, utilizing an energy efficient synthesis technique (e.g.- solution combustion method) with diminishing thermal costs whereas keeping the quality of materials [8]. Our vision on unique advantage of solution combustion method: even in as-burnt powder (no thermal treatment) we get formation of spinel phase with reasonably good magnetic properties [9].

Thus, we give our opinion on the importance of studying time evolution of structural, magnetic properties of $\mathrm{Ni}_{0.5} \mathrm{Zn}_{0.5} \mathrm{Fe}_{2} \mathrm{O}_{4}$ polycrystalline spinel nano ferrites prepared by sol-gel auto-combustion technique.

$\mathrm{Ni}_{0.5} \mathrm{Zn}_{0.5} \mathrm{Fe}_{2} \mathrm{O}_{4}$ nano particles were synthesized by solution combustion method, utilizing citrate-nitrate precursors as explained elsewhere [1]. During synthesis, as soon as the 'dry gel' starts to form, samples were taken out of the reaction vessel (were right away ice-quenched to room temperature) in a time interval ranging between 0-60 minutes, to obtain various stages of the formed ferrite phase. Structural, magnetic parameters of samples were obtained respectively by $\mathrm{Cu}$ $\mathrm{K}_{\alpha} \mathrm{x}$-ray diffraction (XRD), vibration sample magnetometer (VSM).

XRD confirms the single phase (cubic structure, Fd3m space group) in the synthesized samples. Structural parameters were calculated by Rietveld refinement of XRD data by MAUD (Material Analysis Using Diffraction) software [10]. Cation 
distribution was obtained by using XRD intensities, employing Bertaut method, as described by Gastaldi et al. [11]. Figure 1 describes time evolution of structural, magnetic properties, cationic distribution.

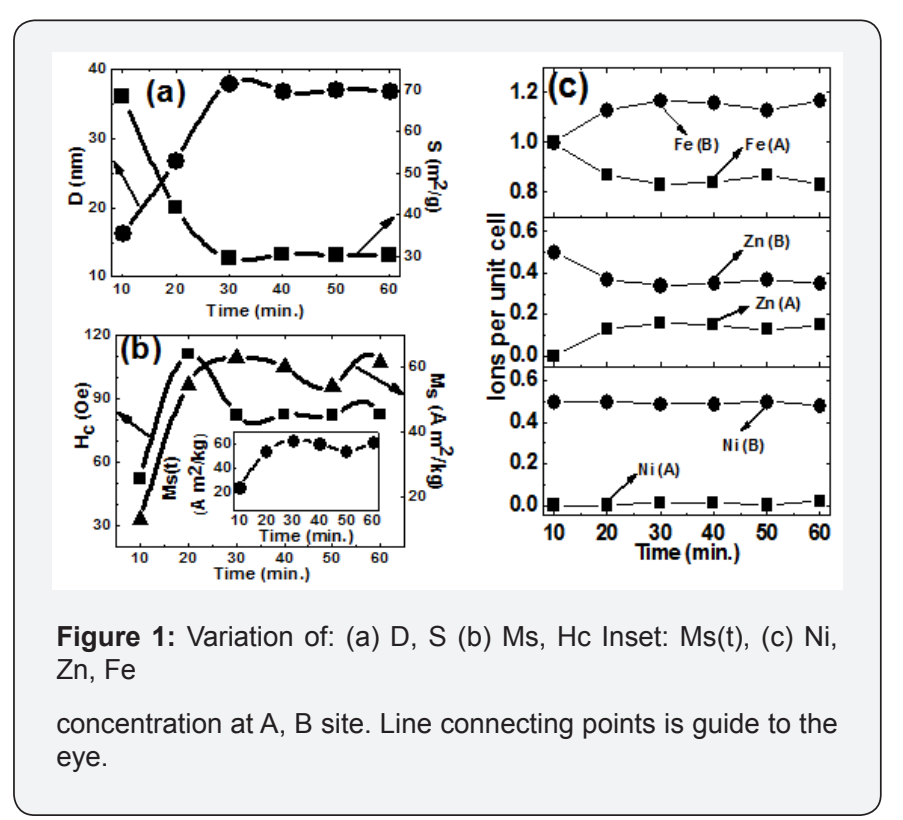

Fig. 1a depicts the variation of particle size D and Specific surface area $\mathrm{S}$ with progression of synthesis time. Perusal of (Figure 1a) D initially increases and saturates after $30 \mathrm{~min}$. synthesis time (range between $16.4 \mathrm{~nm}$ to $38.0 \mathrm{~nm}$ ) suggests particle agglomeration. In ferrites total surface area/unit mass or specific surface area ' $S$ ' has inverse relationship with D (Figure 1a), and is of particular importance for heterogeneous catalysis due of better surface to bulk fraction. Obtained results show that the sample collected after 10 minutes with $\mathrm{S}=68.6 \mathrm{~m}^{2} / \mathrm{g}$ of the synthesis is more appropriate for catalytic activity, instead of other samples, where $\mathrm{S} \sim 30.3 \mathrm{~m}^{2} / \mathrm{g}$.

Fig. 1b displays time evolution of coercivity Hc; Experimental $\mathrm{M}_{\mathrm{s}}\left(\right.$ at $300 \mathrm{~K}$ ), inset theoretical $\mathrm{M}_{\mathrm{s}(\mathrm{t})}$ (at $0 \mathrm{~K}$ ). The $\mathrm{M}_{\mathrm{s}^{\prime}}, \mathrm{H}_{\mathrm{c}}$ increases (Figure $1 \mathrm{~b}$ ) with increasing synthesis time (up to $30 \mathrm{~min}$ ) is attributable to rearrangement of cations at A, B sites (Figure 1c) known to affect magnetic properties [7]. Highest $M_{s}$ of $62.8 \mathrm{~A} \bullet \mathrm{m}^{2} / \mathrm{kg}$, moderate $\mathrm{H}_{\mathrm{c}}$ of $82.10 \mathrm{e}$ was obtained for the $\mathrm{Ni}-\mathrm{Zn}$ sample collected after 30 minutes. Similar variation of $M_{s^{\prime}}, M_{s(t)}$ with time validates the presence of Néel-type magnetic ordering in $\mathrm{Ni}-\mathrm{Zn}$ ferrite. Observed $M_{s^{\prime}}, H_{c}$ values suggest perspective applications of Ni-Zn nano particles in hyperthermia applications [9], synthesized via an energy efficient synthesis process with lower thermal costs while maintaining the material quality. Fig 1c illustrates the cationoccupation of $\mathrm{Ni}^{+}, \mathrm{Zn}^{+}, \mathrm{Fe}^{+}$ions on $\mathrm{A}, \mathrm{B}$ site Perusal of (Figure 1c) depicts that for all the studied samples with increase in synthesis time, $\mathrm{Fe}^{3+}, \mathrm{Ni}^{2+}$ ions remains more populated on B-site (as compared to A-site). It may be noted that absence of any post-preparation thermal treatment encourages a non-equilibrium cation distribution, evident from the presence of $\mathrm{Zn}^{2+}$ ions on both A, B- sites. Presence of both $\mathrm{Ni}$, $\mathrm{Zn}$ in the sample, Ni forces $\mathrm{Zn}$ to move on A-site with increasing synthesis time, only when $\mathrm{Ni}$ replaces $\mathrm{Zn}$, its presence on B-site becomes considerable. Such non monotonous development of the cationic distribution with time will have notable effect on magnetic properties, as seen in (Figure 1b).

\section{Summary}

In summary, energy efficient sol gel auto combustion method has been used to monitor time-progression of structural, magnetic properties of Ni-Zn ferrite. Using these studies, we demonstrate the tenability of magnetic properties, establishing suitability of Ni-Zn ferrites as materials for catalytic, biomedical applications.

This work, SR funded by Project: CSR-IC/CRS-74/ 201415/2104. We thank Dr. M. Gupta, for XRD data.

\section{References}

1. Kane SN, Satalkar M (2017) Correlation between magnetic properties and cationic distribution of $\mathrm{Zn} 0{ }_{85-x} \mathrm{Ni}_{x} \mathrm{Mg}_{0.05} \mathrm{Cu} 0.1 \mathrm{Fe}_{2} \mathrm{O}_{4}$ nano spinel ferrite: effect of Ni doping. J Mater Sci 52(6): 3467-3477.

2. Strom V, Olsson RT, Rao KV (2010) Real-time monitoring of the evolution of magnetism during precipitation of super para magnetic nano particles for bioscience applications. J Mater Chem 20: 41684175.

3. Fernández-GMP, Teixeira JM, Machado P, Oliveira MRFF, Maia JM, et al. (2015) Automatized and desktop AC-susceptometer for the in situ and real time monitoring of magnetic nanoparticles' synthesis by coprecipitation. Rev Sci Instrum 86(4): 043904.

4. Ishino K, Narumiya Y (1987) Development of magnetic ferrites: control and application of losses. Ceram Bull 66(10): 1469-1474.

5. Costa ACFM, Tortella E, Morelli MR, Kiminami RHGA (2003) Synthesis, microstructure and magnetic properties of $\mathrm{Ni}-\mathrm{Zn}$ ferrites. J Magn Magn Mater 256: 174-182.

6. Smit J, Wijn HPJ (1959) Ferrites NV Philip's Gloeilampen-fabrieken, Eindhoven, Holland, Chap. VIII, 136-176.

7. Upadhyay C, Verma HC, Anand S (2004) Cation distribution in nano sized Ni-Zn ferrites. J Appl Phys 95(10): 5746-5751.

8. Rivas P, Sagredo V, Rossi F, Pernechele C, Solzi M, et al. (2013) Structural, magnetic, and optical characterization of $\mathrm{MnFe}_{2} \mathrm{O}_{4}$ nanoparticles synthesized via sol-gel method. IEEE Trans Magn 49: 4568-4571.

9. Coisson M, Barrera G, Celegato F, Martino L, Kane SN, et al. (2016) Hysteresis losses and specific absorption rate measurements in magnetic nano particles for hyperthermia applications. Biochimica et Biophysica Acta doi:10.1016/j.bbagen.2016.12.006

10.Lutterotti L, Scardi P (1990) Simultaneous structure and size-strain refinement by the rietveld method. J Appl Cryst 23(4): 246-252.

11.Gastaldi L, Lapiccirella A (1979) Three different methods of determining the cation distribution in spinels: A comparison. J Sol Stat Cham 30(2): 223-229. 
This work is licensed under Creative Commons Attribution 4.0 Licens DOI: 10.19080/JOJMS.2017.01.555561

\section{Your next submission with Juniper Publishers} will reach you the below assets

- Quality Editorial service

- Swift Peer Review

- Reprints availability

- E-prints Service

- Manuscript Podcast for convenient understanding

- Global attainment for your research

- Manuscript accessibility in different formats ( Pdf, E-pub, Full Text, Audio)

- Unceasing customer service

Track the below URL for one-step submission https://juniperpublishers.com/online-submission.php 